concern; a fungicide used to control a tulip blight in the Netherlands, for example, has triggered a rise in treatment-resistant aspergillosis in people with compromised immune systems. For citrus, the research picture is murky: a few small-scale tests and some previous dosings suggest that using the antibiotics would do little harm - but there is also only limited evidence that the drugs would do much good.

Growers are willing to try anything, however. Citrus greening (also known as huanglongbing, caused by the bacterium Candidatus Liberibacter asiaticus), has crippled the Florida citrus industry: almost half the acreage that was in production before the disease arrived has been abandoned and, by some estimates, $90 \%$ of the state's citrus trees are infected. "The level of desperation is high," says Rick Dantzler, chief operating officer of Florida's Citrus Research and Development Foundation (CRDF) in Lake Alfred.

At this point, the two drugs have worked their way through the regulatory process. Products containing oxytetracycline were approved by the EPA in December, and although final approval for streptomycin has been held up by the federal shutdown in January, growers can use it under an emergency declaration made last year.

\section{LACK OF EVIDENCE}

There is little publicly available science on the long-term use of these drugs in crop settings. "There have not been any studies done so far, at least none that were submitted to the EPA, that looked at whether this use could lead to greater resistance," says Nathan Donley, a senior scientist at the non-profit organization the Center for Biological Diversity in Olympia, Washington.

Critics are particularly galled because there is also little convincing evidence that spraying will keep the scourge at bay. The disease is transmitted by an invasive psyllid insect and moves through the vascular tissue under the tree's bark, a circulatory system that is difficult to access. Emergency applications on citrus crops since 2016 have shown that the antibiotics can slow disease progression, allowing growers to eke a few more harvests out of infected trees. But the drugs do not eliminate greening. "There is no silver bullet," says Taw Richardson, chief executive and president of AgroSource in Tequesta, Florida, which manufactures some of the products that would be sprayed.

What's more, no one has been able to culture Ca. L. asiaticus in the laboratory. So researchers have had to rely on tests in greenhouses and fields to assess the ability of antibiotics to control the disease and the risk of resistance.

An AgroSource report on 17 field trials found that sprayed trees had around a $30 \%$ reduction in leaf loss and a $20 \%$ reduction in early fruit loss (see go.nature.com/2hea1tu). But a compendium of 48 field trials posted online by the CRDF is more equivocal (see go.nature.com $/ 2 \mathrm{u} 6 \mathrm{dksg}$ ). Those trials showed no significant differences between treated and untreated groves in terms of how much fruit the trees yielded, whether trees dropped their fruit early or whether trees looked better or worse.

"It seems that there are a number of growers that are discontinuing using the product, but there are some growers that still believe they are getting a significant benefit," Dantzler says.

The studies are difficult to interpret. Field trials are full of variables: they are conducted in commercial groves, which contain trees of different ages with different rootstocks and grafted elements, and growers are free to choose which additives to use to dilute the active compounds and encourage them to stick to trees.

That heterogeneity extends to the few studies done on antibiotic resistance. "Everybody's doing a different method and measuring different things," says Jeffrey LeJeune, a food safety and quality officer at the Food and Agriculture Organization of the United Nations in Rome, which has been studying the release of antibiotics into the environment. Dantzler says he wishes that the CRDF had had the foresight to study efficacy in a systematic way. By now, it would have had the answers, he says. "As it is, we have only anecdotal evidence based on a compilation of grower surveys."

\section{DO NO HARM}

Academic researchers disagree on how much ecological harm or antibiotic resistance will result.

Graciela Lorca, a microbiologist at the University of Florida in Gainesville who is searching for alternative treatments for citrus greening, warns that the antibiotics are more destructive than growers think. "These antibiotics are really broad-spectrum and they kill tons of bacteria," she says. That includes microbes in and on the trees that are important for preventing other diseases or promoting tree health.

But James Adaskaveg, a plant pathologist at the University of California, Riverside, thinks there is little risk. In anticipation of citrus greening arriving in commercial groves in California, he has been conducting trials of antibiotics on unaffected trees in the university's experimental orchards. (As in Florida, California has sought emergency exemptions to allow antibiotics to be used on commercial citrus trees. So far, however, the only trees found to be infected have been non-commercial ones.)

Adaskaveg's studies have not been published, although the results were sent to the EPA. He says that he sampled bacteria on the leaves of uninfected citrus trees and in the soil around the roots before and after the trees were sprayed using the kind of schedule that citrus growers would six times in a year, alternating between the two drugs to reduce the likelihood that bacteria would adapt. He found no change in the overall count or mix of bacteria, and no rise in resistance. He suggests that perhaps the antibiotics do not remain effective for long, because they are washed off by rain, degraded by sunlight or denatured by enzymes in the soil.

Virginia Stockwell, a plant pathologist at the US Department of Agriculture in Corvallis, Oregon - and, with LeJeune, a co-author of a 2018 white paper on the environmental effects of antibiotics (see go.nature. com/2tbv6hi) - says that tree spraying poses less risk than does livestock dosing. "The microorganisms you find in soil are very different than what you find in a manure pile," she says. "And the amount of antibiotics that those microorganisms in manure would be exposed to is higher, and would be more persistent, than you would have on a sprayed tree or on the soil beneath."

But that, too, is a hypothesis. Whether the drugs control the infection in the long term, and whether they provoke resistance at the same time, cannot be known until Florida or California begins spraying - and even then, little will be understood unless enterprising scientists measure the impact.

The EPA has specified certain rules to reduce the risk of resistance emerging. Spraying is limited to a few times per year; farm workers must wear full protective clothing; and groves cannot be fertilized with uncomposted manure. It has also set a deadline of seven years for re-evaluating the programme, half the time that it would normally impose for an agricultural chemical.

On 13 March, Donley's team and the non-profit federation US Public Interest Research Groups sent the EPA a petition signed by 45,000 people who oppose the measures. Barring a regulatory change of heart, spraying is likely to increase. But scientists are seeking other solutions, including improved pesticides or biological controls to kill the insect vector, nutritional support to keep trees healthier and more targeted delivery mechanisms, such as injecting the drugs directly into the tree's vascular system.

The long-term hope is that scientists can breed a tree that has protection against the bacterium. But that won't happen soon, says Dantzler. "Until we get there, and we're unfortunately a number of years away from it, we've got to find some way to keep the industry alive." - SEE EDITORIALP.283

Maryn McKenna is a science journalist in Atlanta, Georgia, and author of the book Big Chicken, on antibiotic use in animal agriculture. 